\title{
Comparison of two approaches to nutrition education in the management of diabetic patients
}

\begin{abstract}
Introduction: Nutrition education is one of the fundamental axes in the management of diabetes.

Objective: study the impact of two types of nutrition education (personalized and collective) on the glycemic control of diabetics in the province of Kenitra.

Material and methods: The population was composed of 184 patients ( 86 men, 98 women) with an average age of $(51.7 \pm 14.0)$ and an age range of [20 to 88.5]. Data collection was carried out using a questionnaire containing socio-demographic and anthropometric information. Glycemic control was based on fasting glucose (GAJ), postprandial glucose (GPP), and glycated hemoglobin (HbA1c). These analyzes were taken in three separate phases with a duration of 3 months; T0 represents the initial state (before our intervention), $t_{1}$ and $t_{2}$ which represent the values of the three analyzes after our intervention. Participants were randomized into two groups: a group that received collective nutrition education $(n=105)$ and another group $(n=79)$ had a personalized (individual) education. BMI was the only anthropometric measure used.
\end{abstract}

Results: The whole population is overweight (BMI $>25)$ for either women or men, also the results of glycemic control are superior to the norms in the three stages $\left(t_{0}, t_{1}\right.$ or $\left.t_{2}\right)$. Nutrition education Personalized shows statistically significant differences in the variables studied as a function of time more than those studied in collective nutrition education $(\mathrm{p}=0.00<0.05)$. Also the difference is significant between collective nutrition education and personalized nutritional education $(\mathrm{P}=0.00<0.05)$ for the means of HBA1C (\%) at $t_{1}$ and at $t_{2}$; Fasting glucose $(g / 1)$ at $t_{1}$ and $t_{2}$ and post-prandial glucose $(\mathrm{g} / \mathrm{l})$ at $\mathrm{t}_{1}$ and $\mathrm{t}_{2}$.

Conclusion: The results of this study show that collective nutrition education yields significant results in terms of impact on glycemic control of theses diabetics. The number of studies on this aspect (nutrition education) remains modest, another study is desirable on a larger sample to better confirm our results.

Keywords: nutrition education, glycemic control, diabetes, diabetic patients
Volume 8 Issue 2 - 2018

\author{
Lotfi Zeghari,' Youssef Aboussaleh,' Kaoutar \\ Ateilah, ' Asmae Hsaini, I Ali Jafri, ${ }^{2,3}$ Abdelatif \\ Bour ${ }^{4}$ \\ 'Department of Biology, Ibn Tofail University, Morocco \\ ${ }^{2}$ Université Hassan II de Casablanca, Morocco \\ ${ }^{3}$ Université Mohammed VI des Sciences de la Santé, Morocco \\ ${ }^{4}$ Département de Biologie Université Ibn Tofail, Morocco
}

Correspondence: Valentine Pankowski, Department of Chalcolithic and the Bronze Age Archaeology, The National Academy of Sciences of Ukraine, Ukraine, Tel (044) 4I8-9195, Fax (044) 4I8-3306, Email vpns@ukr.net

Received: February II, 2018 | Published: April 09, 2018

\section{Introduction}

Diabetes is a challenging public health problem ${ }^{1}$ because of the complications associated with the disease and In Morocco, diabetes costs reached 206 million US dollars in $2010 .^{2}$ Studies have shown that therapeutic education can reduce mortality and morbidity, and reduce the care costs. ${ }^{3-4}$ Generally, nutrition education is a necessary and essential tool for a good health management ${ }^{5-7}$ by allowing individuals to acquire the necessary skills to be in charge of their wellbeing ${ }^{8}$ and adjusting dietary behaviour to the individual needs of the patient which requires a basic knowledge in good nutrition. ${ }^{9}$ In this study, our objective was to study the impact of two approaches to nutrition education (personalised and collective) on the management of blood glycaemia in patients with type- 2 diabetes.

\section{Methods}

We recruited adult participants who attend the Reference Centre of Diabetes of Kenitra, Morocco - between February 2015 and September 2016. Participants were recruited on the basis of their glycaemic profile: fasting glucose (FG), post-prandial glucose (PPG) and glycated haemoglobin (Hb1Ac). Only patients with a glycaemic disequilibrium were eligible for the study. A total of 200 participants were assigned to two groups: a group which received collective nutrition education sessions $(\mathrm{n}=105)$ and another group whose members received personalised nutrition education $(\mathrm{n}=79)$, the remaining 16 participants dropped out of the study for personal reasons. Anthropometric measurements were collected by a trained staff in accordance with World Health Organization standards. Weight was measured while patients were wearing light clothing and no shoe. Height was measured using a stadiometer graduated in centimetres. Body mass index (BMI) was calculated as weight divided by the square of height $\left(\mathrm{kg} / \mathrm{m}^{2}\right)$. WHO cut-off points for overweight $(B M I \geq 25)$ and obesity (BMI $\geq 30)$ were used as measures of adiposity. A standardized questionnaire was used to collect socio-demographic and personal information about the participants. The glycaemic profile was assessed based on FG, PPG and Hb1Ac. Blood analyses were conducted at T0, T1 and T2, at intervals of three months each. T0 was at the baseline before our intervention. T1 and T2 were respectively after 3 months and 6 months of the beginning of our intervention.

Collective sessions consisted of workshops, at a frequency of two workshops per month, with the participation of a maximum of 
15 patients that were coached by a dietician using information cards in the case of roundtables and focus groups or using presentation in the case of educational trainings. This group received a total of 18 sessions during this study. Individual sessions consisted of individual consultations of 20 minutes (two sessions per week) with a dietician who provides personalized counselling based on the condition of the patient and their glycaemic profile. At the end of the session, the dietician provides the patient with a dietary programme to be followed until the following session. Statistical analysis was conducted using SPSS statistical package (version 18)

\section{Results}

Participants were aged between 20 and 89 years old $(51.7 \pm 14.0)$. Table 1 represents the different parameters of the participants at the study baseline for both groups. All study participants were overweight $($ BMI $>25)$. Personalized nutritional education had a more significant impact on the studied parameters than the collective sessions (Table 2). The difference between PNE and GNE is significant for Hb1Ac $(\%)$, fasting glucose and post-prandial glucose between $t_{1}$ and $t_{2}$ (Table 3).

Table I Anthropometric and biologic parameters of the study participants at baseline $(\mathrm{N}=184)$

\begin{tabular}{|c|c|c|c|c|c|c|c|c|c|}
\hline & & $\mathbf{N}$ & Weight & Height & Age & BMI & HbAlc & FG & PPG \\
\hline \multirow[t]{3}{*}{ CNE } & Total & 105 & $77,89 \pm 14,5$ & $164 \pm 10$ & $54,2 \pm 14$ & $28,8 \mid \pm 5,90$ & $10,10 \pm 1,74$ & $2,83 \pm 0,73$ & $3,40 \pm 0,88$ \\
\hline & $M$ & 58 & $77,32 \pm 13,7$ & $170 \pm 7$ & $51.3 \pm 15,8$ & $26,55 \pm 4,82$ & $10.13 \pm 1.78$ & $2.84 \pm 0.79$ & $3.35 \pm 0.72$ \\
\hline & $\mathrm{F}$ & 47 & $78,6 \pm 15,55$ & $157 \pm 8$ & $57.7 \pm 10,7$ & $3 I, 6 I \pm 4,96$ & $10.07 \pm 1.70$ & $2.80 \pm 0.65$ & $3.47 \pm 1.05$ \\
\hline \multirow[t]{3}{*}{ PNE } & Total & 79 & $71,09 \pm 15,5$ & $166 \pm 7$ & $48,3 \pm 13,3$ & $27,05 \pm 4,96$ & $11,15 \pm 2,14$ & $3,07 \pm 0,8 \mathrm{I}$ & $3,82 \pm 0,88$ \\
\hline & $M$ & 28 & $70,36 \pm 12,9$ & $|7| \pm 5$ & $46.4 \pm 12,1$ & $24,47 \pm 4,15$ & $11.27 \pm 2.16$ & $3.21 \pm 0.77$ & $3.92 \pm 0.88$ \\
\hline & $\mathrm{F}$ & 51 & $71,49 \pm 16,9$ & $163 \pm 6$ & $49.4 \pm 13,9$ & $28,46 \pm 4,82$ & $11.09 \pm 2.14$ & $2.99 \pm 0.82$ & $3.77 \pm 0.88$ \\
\hline Total & & 184 & $74,97 \pm 15,3$ & $165 \pm 9$ & $51,7 \pm 14$ & $28,05 \pm 5,57$ & $10,55 \pm 1,98$ & $2,93 \pm 0,77$ & $3,58 \pm 0,90$ \\
\hline
\end{tabular}

CNE, Collective nutritional education group; PNE, Personalized nutritional education group.

Table 2 The impact of personalized and collective nutritional education on HbAlc, fasting glucose (FG) and post-prandial glucose (PPG) of a group of patients with type-2 diabetes $(\mathrm{N}=184)$

\begin{tabular}{|c|c|c|c|c|c|}
\hline & Value & unction of $t$ & $(M ; \sigma)$ & $\begin{array}{l}\text { Matched } \\
\text { Differences }(M ; \sigma)\end{array}$ & $T$ test \\
\hline \multirow{10}{*}{ 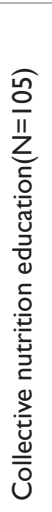 } & Pair I & HBAIC (\%) à t $t_{0}$ & $(10,10 ; 1,7)$ & $(0,49 ; 1,6)$ & $(t=3,1 ; p=0,002<0,05 ; D S)^{\prime}$ \\
\hline & Palr 1 & HBAIC (\%) à $t_{1}$ & $(9,62 ; 1,6)$ & $(0,49 ; 1,6)$ & $(\mathrm{t}=3,1 ; \mathrm{p}=0,002<0,05 ; \mathrm{D})$ \\
\hline & Pair 2 & HBAIC (\%) à $t_{1}$ & $(9,62 ; 1,6)$ & $(0,64 ; 1,5)$ & $(\mathrm{t}=4,4 ; \mathrm{p}=0,00<0,05 ; \mathrm{DS})$ \\
\hline & ralr 2 & HBAIC (\%) à t $t_{2}$ & $(8,98 ; 1,7)$ & $(0,04,1,0)$ & $([-4,4, p-0,00<0,0 J, D د)$ \\
\hline & Pair 3 & $\mathrm{FG}(\mathrm{g} / \mathrm{l})$ à t & $(2,83 ; 0,7)$ & $(0,01 ; 1,1)$ & $(\mathrm{t}=0, \mathrm{I} ; \mathrm{p}=0,89<0,05 ; \mathrm{NS})^{2}$ \\
\hline & Palr 3 & $\mathrm{FG}(g / l)$ à t $\mathrm{t}_{1}$ & $(2,81 ; 0,9)$ & $(0,01 ; 1,1)$ & $(\mathrm{t}=0, \mathrm{I} ; \mathrm{p}=0,89<0,05 ; \mathrm{NS})^{2}$ \\
\hline & Pair 4 & $F G(g / l)$ à t & $(2,81 ; 0,9$ & $(0,21 ; 0,5)$ & $(\mathrm{t}=4,5 ; \mathrm{p}=0,00<0,05 ; \mathrm{DS})$ \\
\hline & & $\mathrm{FG}(\mathrm{g} / \mathrm{l}) \mathrm{à} \mathrm{t}_{2}$ & $(2,60 ; 0,9)$ & & \\
\hline & Pair 5 & PPG $(g / l)$ à $t_{0}$ & $(3,40 ; 0,9)$ & $(0,09 ; 1,1)$ & $(\mathrm{t}=-0,8 ; \mathrm{p}=0,43<0,05 ; \mathrm{NS})$ \\
\hline & & PPG $(g / l)$ à $t_{1}$ & $(3,49 ; 0,7)$ & ( & \\
\hline \multirow{13}{*}{ 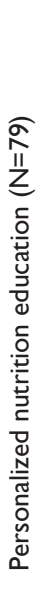 } & Pair 6 & PPG $(g / l)$ à $t_{1}$ & $(3,49 ; 0,7$ & $(0,37 ; 0,5)$ & $(\mathrm{t}=7,3 ; \mathrm{p}=0,00<0,05 ; \mathrm{DS})$ \\
\hline & 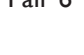 & PPG $(g / l)$ à $t_{2}$ & $(3,12 ; 0,5$ & (ט, (כ, ) & ) \\
\hline & Pair I & HBAIC (\%) à & $(I I, \mid 15: 2, I)$ & $(2,49 ; 2,2)$ & $(\mathrm{t}=9,8 ; \mathrm{p}=0,00<0,05 ; \mathrm{DS})$ \\
\hline & & HBAIC (\%) à t & $(8,66 ; 1, I)$ & & \\
\hline & Pair 2 & HBAIC (\%) à t & $(8,66 ; 1,1)$ & $(I, 3 ; I, I)$ & $(\mathrm{t}=9,8 ; \mathrm{p}=0,00<0,05 ; \mathrm{DS})$ \\
\hline & I ail 2 & HBAIC (\%) à $t_{2}$ & $(7,40 ; 0,6)$ & $(1,0,1,1)$ & \\
\hline & Pair 1 & $\mathrm{FG}(\mathrm{g} / \mathrm{l}) \mathrm{à}$ & $(3,07 ; 0,8)$ & $(1: 0.7)$ & $(t=128 ; p=0,00<0,05: D S)$ \\
\hline & & $\mathrm{FG}(\mathrm{g} / \mathrm{I})$ à $\mathrm{t}_{1}$ & $(2,10 ; 0,7)$ & $(1 ; 0,7)$ & \\
\hline & Pair 2 & $F G(g / l)$ à $t_{1}$ & $(2,10 ; 0,7)$ & $(0,6 ; 0,4)$ & $(t=13,5 ; p=0,00<0,05 ; D S)$ \\
\hline & & $F G(g / l)$ à $t_{2}$ & $(I, 52 ; 0,5)$ & & \\
\hline & Pair 1 & PPG $(g / l)$ à & $(3,82 ; 0,8)$ & $(1.06)$ & $(1-142 \cdot 0=000<005.00$ \\
\hline & Palr 1 & PPG $(g / l)$ à $t_{1}$ & $(2,83 ; 0,7)$ & $(1,0,6)$ & $(\tau--14,3, p-0,00<0,03, \mathrm{D})$ \\
\hline & Pair 2 & PPG $(g / l)$ à $t_{1}$ & $(2,83 ; 0,7)$ & $(0,7 ; 0,5)$ & $(\mathrm{t}=\mid 4,2 ; \mathrm{p}=0,00<0,05 ; \mathrm{DS})$ \\
\hline
\end{tabular}

FG, fasting glucose; PPG, post-prandial glucose. 
Table 3 The difference between GNE and PNE at $t_{0}, t_{1}$ and $t_{2}$ in a group of patients with type-2 diabetes $(N=184)$

\begin{tabular}{|c|c|c|c|}
\hline $\begin{array}{l}\text { Values as a function } \\
\text { of time }\end{array}$ & $\begin{array}{l}\text { Collective } \\
\text { nutrition } \\
\text { education }(N=105)\end{array}$ & $\begin{array}{l}\text { Personalized } \\
\text { nutrition } \\
\text { education }(\mathrm{N}=79)\end{array}$ & $Z$ test \\
\hline & $(M ; \sigma)$ & $(M ; \sigma)$ & \\
\hline L'HBA IC (\%) à t & $(11,10 ; 1,7)$ & $(I I, 15 ; 2,1)$ & $(z=-3,6 ; p=0,06>0,05 ; N S)^{*}$ \\
\hline L'HBAIC (\%) à t & $(9,62 ; 1,6)$ & $(8,66 ; 1, I)$ & $(z=4,4 ; p=0,00<0,05 ; D S)$ \\
\hline L'HBAIC (\%) à $t_{2}$ & $(8,98 ; 1,7)$ & $(7,40 ; 0,6)$ & $(z=7,7 ; p=0,00<0,05 ; D S)$ \\
\hline$F G(g / l) a ̀ ~ t_{0}$ & $(2,83 ; 0,7)$ & $(3,07 ; 0,8)$ & $(\mathrm{z}=-2, \mathrm{I} ; \mathrm{p}=0,36<0,05 ; \mathrm{NS})^{*}$ \\
\hline$F G(g / l)$ à $t_{1}$ & $(2,81 ; 0,9)$ & $(2,10 ; 0,7)$ & $(z=5,7 ; p=0,00<0,05 ; D S)$ \\
\hline$F G(g / l)$ à $t_{2}$ & $(2,60 ; 0,8)$ & $(1,52 ; 0,5)$ & $(z=10,6 ; p=0,00<0,05 ; D S)$ \\
\hline PPG $(g / l)$ à $t_{0}$ & $(3,76 ; 0,8)$ & $(3,82 ; 0,8)$ & $(z=-3,2 ; p=0,07>0,05 ; N S)$ \\
\hline PPG $(g / l)$ à $t_{1}$ & $(3,49 ; 0,7)$ & $(2,83 ; 0,6)$ & $(z=6,4 ; p=0,00<0,05 ; D S)$ \\
\hline PPG (g/l) à t ${ }_{2}$ & $(3,12 ; 0,53)$ & $(2,08 ; 0,40)$ & $(z=14,3 ; p=0,00<0,05 ; D S)$ \\
\hline
\end{tabular}

DS, The difference is significant; NS, The difference is not significant.

\section{Discussion}

Current dietary habits are associated to 4 among the 10 most frequent causes of mortality in the world, including diabetes. ${ }^{10}$ According to the WHO estimates, non-communicable diseases are accountable for $75 \%$ of the mortality rates in Morocco in 2008, diabetes alone is accountable for $12 \%$ of these rates. ${ }^{11}$ In 2008 , the prevalence of individuals with a raised blood glycaemia was $9.9 \% .{ }^{12}$ Nutritional education aims to assist individuals on voluntarily improve their dietary habits and adopting healthier nutritional choices. ${ }^{13}$ Educating a diabetic patient is an essential component in the management of diabetes and which benefits include a more comprehensive management and care of the disease. ${ }^{14}$ However, very few people benefit from counselling and dietary recommendations to be able to take care of themselves. In this study, we compared to approaches to nutrition education in adult diabetic patients; a collective approach and a personalized approach. Participants of both groups showed an improvement in their glycaemic profile (Hb1Ac, FG and PPG) during the intervention $\left(\mathrm{T}_{0}, \mathrm{~T}_{1}\right.$ and $\left.\mathrm{T}_{2}\right)$. However, the improvement that the PNE has showcased was more significant in all of the three studied parameters.

These results are consistent with previous similar studies conducted among diabetic patients in other countries ${ }^{15-19}$ and suggest that nutrition education can be effective in helping these patients with their condition. Several studies have explored the efficiency of different interventions aiming at improving the management of diabetes, especially in vulnerable populations ${ }^{20,21}$ and despite the difference in the approaches, they observed a decreasing Hb1 Ac. ${ }^{20-22}$ In addition to the demonstrated advantages of nutritional counselling in improving the biologic parameters of diabetic patients in Morocco, our study compared two approaches to nutrition education and revealed a higher efficiency of an individual approach which has the advantages of being personalized and specific to the patient's profile, which consistent with previous findings. ${ }^{23}$ The management of diabetes in Morocco is rare and very costly. Thus, it is important to equip patients with the specific knowledge to correctly manage their disease and avoid further complications, especially in a society with many economic challenges. The relatively easy reproducibility of the intervention and its minimal cost are two major factors that would allow its implementation in the standard care of type- 2 diabetes in vulnerable communities.

\section{Conclusion}

Collective and individual nutrition education are both efficient in improving the glycaemic profile of patients with type-2 diabetes in vulnerable individuals with a low level of education and lacking knowledge of nutritional recommendations to properly manage their condition. Individual and personalized nutrition education has proven to be the most efficient approach and should be recommended for critical and advanced cases, while collective sessions can be very helpful to support new diabetic patients and offer the very much needed psychological support.

\section{Acknowledgements}

The authors gracefully acknowledge the help and support of the medical and nursing staff of the Centre of Reference for Diabetes in Kenitra, Morocco.

\section{Conflict of interest}

The authors declare that they have no conflicts of interest in relation to Article.

\section{References}

1. Lefèbvre P, Le diabète hier, Aujourd'hui, et al. demain: L'action de la fédération internationale du diabète. Revue médicale de Lì̀ge. 2005;60(56):273-277.

2. Zhang $\mathrm{P}$, Zhang $\mathrm{X}$, Brown J, et al. Global healthcare expenditure on diabetes for 2010 and 2030. Diabetes research and clinical practice. 2010;87( 3):293-301. 
3. Stratton, Irene M, Adler, et al. Association of glycaemia with macrovascular and microvascular complications of type 2 diabetes (UKPDS 35). Prospective observational study. 2000;321(7258):405-412.

4. Shichiri, Motoaki, Kishikawa, et al. Long-term results of the Kumamoto Study on optimal diabetes control in type 2 diabetic patients. Diabetes care. 2000;23:B21.

5. Aboussaleh Y, Farsi M, El hioui M, et al. Transition nutritionnelle au Maroc. Coexistence de l'anémie et de l'obésité chez les femmes au Nord Ouest marocain. 2009;19:67-74.

6. LotfiZeghari, Youssef Aboussaleh, RachidSbaibi. Assessment of nutritional knowledge of athletes in kenitra city. The American Journal of Innovative Research and Applied Sciences.2015;1(6):209-213.

7. Purcell, Laura K. Sport nutrition for young athletes. Paediatrics\& child health. 2013;18(4):200-202.

8. Jourdan, Didier. Quelle éducation nutritionnelle à l'école. La santé de l'homme. 2004;374:26-29.

9. Burke, Louise. Practical issues in nutrition for athletes. Journal of Sports Sciences.1995;13(S1):S83-S90.

10. Contento, Isobel R. Nutrition education. Linking research, theory, and practice. Asia Pac J Clin Nutr. 2008;17(Suppl 1):176-179.

11. World health organization. Noncommunicable diseases country profiles; 2014.

12. World health organization. Noncommunicable diseases country profiles; 2011.

13. Hawkes C. Promoting healthy diets through nutrition education and changes in the food environment. An international review of actions and their effectiveness. 2013;91-92.

14. Cooper HC, Booth k, Et gill G. Patients perspectives on diabetes health care education. Health education research. 2003;18(2):191-206.
15. Chapin, Rebecca B, williams, et al. Diabetes control improved when innercity patients received graphic feedback about glycosylated hemoglobin levels. Journal of general internal medicine. 2003;18(2):120-124.

16. Melkus, Gail D, Eramo, et al. A culturally competent intervention of education and care for black women with type 2 diabetes. Applied Nursing Research. 2004;17(1):10-20.

17. Philis-Tsimikas, Athena, Fortmann, et al. Peer-led diabetes education programs in high-risk Mexican Americans improve glycemic control compared with standard approaches. Diabetes care. 2011;34(9):19261931.

18. Middelkoop, Garendjc, Geelhoed-Duijvestijn, et al. Effectiveness of culture-specific diabetes care for Surinam South Asian patients in the Hague. Diabetes Care. 2001;24(11):1997-1998.

19. De labry lima, Antonio olry, Tamayo, et al. Effectiveness of an intervention to improve diabetes self-management on clinical outcomes in patients with low educational level. Gaceta sanitaria. 2017;31(1):40-47.

20. Glazier, Richard H, Bajcar, et al. A systematic review of interventions to improve diabetes care in socially disadvantaged populations. Diabetes care. 2006;29(7):1675-1688.

21. Gucciardi, Enza, Chan, et al. A systematic literature review of diabetes self-management education features to improve diabetes education in women of Black African/Caribbean and Hispanic/Latin American ethnicity. Patient education and counseling. 2013;92(2):235-245.

22. Hawthorne, Kamila, Robles, et al. Culturally appropriate health education for type 2 diabetes mellitus in ethnic minority groups. Cochrane Database Syst Rev. 2008:3.

23. Ricci-cabello, Ignacio, Ruiz-pérez, et al. Characteristics and effectiveness of diabetes self-management educational programs targeted to racial/ ethnic minority groups.A systematic review, meta-analysis and metaregression. BMC endocrine disorders. 2014;14(1):60. 